\title{
Gender Differences in South African Generation Y Students' Motives for Engaging in Physical Activity
}

\author{
Ms. Natanya Meyer \\ North-West University (Vaal Triangle Campus) \\ natanya.meyer@nwu.ac.za \\ Prof Ayesha Lian Bevan-Dye \\ North-West University (Vaal Triangle Campus) \\ ayeshabevandye@gmail.com
}

Doi:10.5901/mjss.2014.v5n21p195

\begin{abstract}
Whilst the literature provides significant evidence of the benefits of engaging in physical activity and its influence on reducing certain dreaded illnesses, there are indications that the levels of physical activity amongst the youth are declining globally. The Generation Y cohort comprises individuals born between 1986 and 2005, and in 2013, this cohort made up an estimated 38 percent of the South African population. As today's youth, this cohort's physical and mental wellbeing has important current and future economic implications, not only to the country's health care system but also to its labour market. Successfully encouraging members of this cohort to engage in physical activity necessitates having a clear understanding of their motives to participate in physical activity. The purpose of this study was to determine whether gender differences exist concerning Generation Y students' motivation for participating in physical activity. A survey questionnaire that included the Exercise Motivation Inventory-2 (EMI-2) was administered on a sample of 450 students registered at the campuses of three higher education institutions (HEIs) in the Gauteng Province of South Africa. The captured data was analysed using descriptive statistics and a two-independent samples t-test. The findings suggest that Generation $Y$ females are more motivated to engage in physical activity by the motives of health pressure, ill-health avoidance, positive health, weight management and appearance. In contrast, Generation $Y$ males are more motivated to engage in physical activity by intrinsic motives such as enjoyment, challenge, competition, and strength and endurance.
\end{abstract}

Keywords: Physical activity; exercise participation; Generation Y; gender differences

\section{Introduction}

Whilst the literature provides significant evidence of the benefits of engaging in physical activity and its influence on reducing certain dreaded illnesses, there are indications that the levels of physical activity amongst the youth are declining globally (Ahmed, 2012; Nolan et al., 2011). The Generation Y cohort comprises individuals born between 1986 and 2005 (Markert, 2004), and in 2013, this cohort made up an estimated 38 percent of the South African population (Statistics South Africa, 2013). As today's youth, this cohort's physical and mental wellbeing has important current and future economic implications, not only to the country's health care system but also to its labour market.

Historically, people's youth has been viewed as the life stage at which they are the healthiest. However, there are indications that the occurrence of obesity and the associated risks of developing non-communicable diseases such as heart problems, high blood pressure, diabetes and the like is on the rise amongst the youth worldwide and constitutes a serious public challenge in the twenty-first century (WHO, 2014a). Participating in physical activity, particularly participation in persistent exercise, aids significantly in preventing or counteracting obesity and mitigating the risk of developing non-communicable diseases (WHO, 2011).

Health risk behaviour amongst the youth in South Africa is also prevalent and includes substance abuse, unsafe sex, unhealthy eating behaviour and a lack of participation in physical activity (Shilubane et al., 2013). According to Rossouw et al. (2012), obesity tends to be higher amongst young South African females than males, and this is primarily because females engage in less physical activity. Given the known physical and psychological benefits of physical activity, there is a need to engage in increased social marketing efforts directed at encouraging greater participation in physical activity amongst the South African youth. 
Designing successful social marketing campaigns aimed at encouraging members of the Generation $Y$ cohort to engage in physical activity necessitates having a clear understanding of their motives to participate in physical activity. Moreover, understanding the gender differences in these motives will aid in designing tailored marketing campaigns, thereby maximising the persuasiveness of such marketing communications. As such, the purpose of this study was to determine whether gender differences exist concerning Generation $Y$ students' motivation for participating in physical activity.

\section{Benefits of Physical Activity and Physical Exercise}

The WHO (2011) defines physical activity as "any bodily movement produced by the skeletal muscles that uses energy" and indicates that this includes participating in sports, exercising, playing, walking or doing household chores. In comparison to the broadly defined physical activity, exercise refers to the planned, structured and repetitive activity with a specific goal or purpose (Caspersen et al., 1985).

Over and above the obvious physical benefits, participating in physical activity, especially regular exercise offers several additional benefits to individuals, especially members of the Generation $Y$ cohort, such as psychological benefits, social benefits, and avoidance of risky behaviour benefits (WHO, 2014b). The psychological benefits of physical activity include stress reduction, reduced depression and improved self-esteem (Maltby \& Day, 2001). The social benefits for the Generation Y cohort relate to physical activity and exercise providing the opportunity for social development through social interaction and social integration (WHO, 2014b). There are also indications that risky behaviour, such as violence, substance abuse and unsafe sex (Shilubane et al., 2013) are less likely amongst Generation Y individuals who regularly engage in physical activity and exercise (WHO, 2014b).

In light of the physical, psychological, social and avoidance of risky behaviour associated with engaging in physical activity and exercise, it seems imperative that the youth be encouraged to become more active, which requires an understanding of their motives for participating in physical activity.

\section{Motives for Engaging in Physical Exercise}

From a social science perspective, motivation is typically explained as the psychological processes that trigger the arousal, direction and persistence of behaviour (Mitchell, 1982) and encompasses all aspects of activation and intension (Ryan \& Deci, 2000). In the realm of sports and exercise, motivation is considered a key determinant of athletic performance and persistence in following an exercise regime (Vallerand, 2012), and motivation and youth participation in physical activity are considered key topics in sport psychology literature (Spray et al., 2006). Vallerand (2012) indicates that in terms of sport and physical activity participation, it is useful to differentiate between intrinsic motivation and extrinsic motivation. This is in accordance with the Deci and Ryan (1985) theory of self-determination that distinguishes between doing something for enjoyment and satisfaction (intrinsic motivation) and doing something in order to gain a reward that falls outside of the actual behaviour (extrinsic motivation). Motives such as wealth, attractiveness and fame are examples of extrinsic aspirations, whilst motives such as personal development and affiliation are examples of intrinsic aspirations (Ryan \& Deci, 2008). Taking cognisance of the theory of self-determination and the distinction between intrinsic and extrinsic motives, Markland and Hardy (1993) developed the 12 factor Exercise Motivation Inventory (EMI), which encompasses intrinsic motives such as enjoyment, personal development, affiliation, recreation, stress management, competition and fitness, and extrinsic motives such as weight management, social recognition, appearance, ill-health avoidance and health pressures.

Owing to several weaknesses in the EMI, Markland and Ingledew (1997) set out to refine and improve the original EMI and developed the EMI-2. The 14 factor EMI-2 comprises psychological motives (stress management, revitalisation, enjoyment, challenge), which are intrinsic motives, interpersonal motives (social recognition, affiliation, competition) and health motives (health pressure, ill-health avoidance, positive health), which contain both intrinsic and extrinsic motives, body-related motives (weight management, appearance), which are extrinsic motives and fitness motives (strength and endurance, and nimbleness), which are intrinsic motives. Ingledew, Markland and Medley (1998) suggest that while extrinsic motives typically drive people to start participating in physical activity exercise, intrinsic motives determine the long-term adherence to such regimes.

\section{Gender and Physical Activity}

The issue of gender difference has received increased attention over the past few decades, including in research 
pertaining to participation in physical activity (Drake et al., 2014; Ghooshchy et al., 2011; Roxas \& Stoneback, 2004). There are two assumptions within classical research on gender socialisation. First, gender identity is considered an unchanging personality element, which will remain stable over time and during different situations. Secondly, differences between males and females are due to internalisation of gender identity as defined by the ideals and outlooks of a cultural setting (Chalabaev et al., 2013). This may be better explained by considering some of the factors that influence an individual's participation in physical activity. These factors include influence from family, such as the influence of a parent or older sibling, school, such as the influence of a friend and peer groups, such as sporting teams or clubs. In most cases, males are influenced more positively than females regarding each of the three factors (Vilhjalmsson \& Kristjansdottir, 2003).

Gender studies regarding physical participation are important for designing and implementing the correct education and training programmes aimed at attracting male and female participation (Roxas \& Stoneback, 2004). Sebire et al. (2009) report that their findings indicate that females have a significantly greater exercise anxiety than males, significantly lower self-worth and report exercising significantly less.

One study found that females were motivated to engage in sport more by extrinsic motives such as weight management and appearance, whilst males were motivated by intrinsic motives such as competition and social engagement (Koivula, 1999). Drake et al. (2014) indicates that one of the main motivators for male sport participation is competition. In a study utilising the EMI-2, findings suggest that males are more motivated to exercise by the intrinsic goals of affiliation, challenge, competition, enjoyment and fitness. In contrast, females were more motivated to exercise by the extrinsic goals of weight management, appearance, health pressure and ill-health avoidance (Kilpatrick et al., 2005). Similarly, Rintaugu and Ngetich (2012) found males to be more motivated by the strength and endurance, enjoyment and skill development motives and females by the fitness, weight management and appearance, and revitalisation motives.

Ingledew and Markland (2008) suggest that appealing to pre-existing motives in social marketing campaigns, even if those motives are extrinsic in nature, may be beneficial in encouraging targeted segments to engage in physical activity and exercise initially but that such campaigns need to also appeal to intrinsic motives in order to sustain long-term participation.

\section{Methodology}

\subsection{Sample}

The initial sampling frame included South Africa's 23 registered public higher education institutions (HEl's) that existed in 2013. Using judgement sampling, this sampling frame was narrowed down to include the campuses of three HEls situated in the Gauteng province - one from a comprehensive university, one from a traditional university and one from a university of technology.

Thereafter, a non-probability convenience sample of 450 students across the three campuses was taken. Lecturers at each of the three campuses were contacted and asked if they would allow the questionnaire to be distributed to their students. Once permission was obtained, fieldworkers were used to distribute the questionnaires to students at the three campuses. Participation was on a voluntary basis and full confidentiality was assured concerning the information provided by the participants, including the name of the HEl at which they were registered.

\subsection{Instrument and procedure}

A self-administered survey questionnaire was used to gather the required data. The Exercise Motivation Inventory (EMI2) (Markland \& Ingledew, 1997) was used to measure the Generation $Y$ students' motives for engaging in physical activity. The scale comprises the five subscales labelled psychological motives (stress management (four items), revitalisation (four items), enjoyment (four items), challenge (five items)), interpersonal motives (social recognition (four items), affiliation (four items), competition (four items)), health motives (health pressure (three items), ill-health avoidance (four items), positive health (four items)), body-related motives (weight management (four items), appearance (four items)), and fitness motives (strength and endurance (four items) and nimbleness (four items)). These scaled responses were measured on a six-point Likert scale ranging from strongly disagree (1) to strongly agree (6). The Likert scale was selected as it is the most popular interval scale for the measurement of attitudes and offers the advantages of being both easy to construct and easy to administer (Malhotra, 2010).

The questionnaire included demographic questions relating to mother-tongue language, province of origin, age, 
race and gender. These questions were included to assess how representative to sample was of the target population.

The questionnaire was pilot tested on 30 students, who were excluded from the final study. The pilot study was conducted in order to evaluate the reliability of the instrument. The Cronbach alpha values computed for the individual constructs ranged between 0.825 and 0.963 in the pilot study, thereby indicating satisfactory reliability (Pallant, 2010). The captured data was analysed using the Statistical Package for Social Sciences (IBM SPSS), Version 22.

\subsection{Results}

Following the distribution of 450 questionnaires across the three campuses, 324 completed and usable questionnaires were returned. The sample included an equal split between male and female participants. The sample was made up of participants from all seven of the age categories specified in the target population, with the majority (47\%) indicating being 19 and 20 years of age. In addition, the sample included participants from eight of South Africa's nine provinces. The majority of participants indicated their province of origin as Gauteng (53.6\%), followed by Limpopo (15.4\%). There were no participants from the Western Cape. The sample comprised predominantly African/black students (84\%) and white students (13.6\%), which mirrors the ethnic spread of the South African population. A description of the sample is provided in Table 1.

Table 1: Sample description

\begin{tabular}{|c|c|c|c|c|c|c|c|c|c|}
\hline Age & $(\%)$ & Gender & $(\%)$ & Language & $(\%)$ & Home Province & $(\%)$ & Race & $(\%)$ \\
\hline 18 & 12.3 & Female & 50.0 & Afrikaans & 9.6 & Eastern Cape & 3.8 & Coloured & 1.5 \\
\hline 19 & 21.6 & Male & 50.0 & English & 8.7 & Free State & 11.0 & Indian/Asian & 0.9 \\
\hline 20 & 25.0 & & & IsiNdebele & .3 & Gauteng & 53.6 & White & 13.6 \\
\hline 21 & 17.6 & & & IsiXhosa & 7.1 & KwaZulu- Natal & 5.3 & African/Black & 84.0 \\
\hline 22 & 11.4 & & & IsiZulu & 19.6 & Limpopo & 15.4 & & \\
\hline 23 & 8.3 & & & Sesotho sa Leboa & 7.8 & Mpumalanga & 5.0 & & \\
\hline \multirow[t]{5}{*}{24} & 3.7 & & & Sesotho & 23.6 & North West & 4.4 & & \\
\hline & & & & Setswana & 10.6 & Northern Cape & 1.6 & & \\
\hline & & & & SiSwati & 4.3 & & & & \\
\hline & & & & Tshivenda & 3.4 & & & & \\
\hline & & & & Xitsonga & 5.0 & & & & \\
\hline
\end{tabular}

In order to assess the reliability of the measurement instrument in the main survey, the Cronbach alpha values for each of the 14 constructs were calculated. Table 2 reports on these alpha values, together with the mean and standard deviation scores computed for the overall sample.

Table 2: Motives for engaging in physical exercise and level of physical exercise

\begin{tabular}{lccc}
\hline & Mean N= 324 & Standard deviation & Alpha \\
\hline Motives & & & \\
\hline Stress management & 4.68 & 1.04 & 0.786 \\
Revitalisation & 4.75 & 0.95 & 0.726 \\
Enjoyment & 4.78 & 1.05 & 0.838 \\
Challenge & 4.61 & 0.96 & 0.803 \\
Social recognition & 3.58 & 1.44 & 0.877 \\
Affiliation & 4.21 & 1.17 & 0.807 \\
Competition & 4.21 & 1.39 & 0.905 \\
Health pressure & 3.34 & 1.56 & 0.776 \\
III-health avoidance & 4.86 & 1.20 & 0.860 \\
Positive health & 5.23 & 0.94 & 0.907 \\
Weight management & 4.08 & 1.41 & 0.853 \\
Appearance & 4.41 & 1.19 & 0.785 \\
Strength and endurance & 4.85 & 1.04 & 0.811 \\
Nimbleness & 4.70 & 1.02 & 0.807 \\
\hline
\end{tabular}

The reliability coefficients for the scales in the main survey were all above the recommended 0.700 level (Pallant, 2010), 
which confirmed that the internal consistency reliability of the individual constructs in the measurement instrument. The highest means were recorded for the positive health motive (mean=5.23), the ill-health avoidance motive (mean=4.86) and the strength and endurance motive (mean=4.85). The lowest mean was recorded on the health pressure motive (mean=3.34), which, given the age of the target population, was to be expected.

A two-independent samples t-test was then conducted in order to determine whether male and female Generation $Y$ students differ in their motives to engage in physical exercise. The significance level was set at $a=0.05$ level. The results of this analysis are reported on in Table 3.

Table 4: Gender differences

\begin{tabular}{|c|c|c|c|c|c|}
\hline Motives & Female mean & Male mean & Mean difference & t-score & p-value \\
\hline \multicolumn{6}{|l|}{ Psychological motives } \\
\hline Stress management & 4.75 & 4.62 & 0.133 & 1.148 & 0.252 \\
\hline Revitalisation & 4.76 & 4.75 & 0.006 & 0.058 & 0.954 \\
\hline Enjoyment & 4.65 & 4.91 & -0.258 & -2.233 & $0.026^{*}$ \\
\hline Challenge & 4.43 & 4.79 & -0.359 & -3.433 & $0.001 *$ \\
\hline \multicolumn{6}{|l|}{ Interpersonal motives } \\
\hline Social recognition & 3.42 & 3.74 & -0.315 & -1.979 & 0.049 \\
\hline Affiliation & 4.15 & 4.27 & -0.119 & -0.914 & 0.362 \\
\hline Competition & 3.92 & 4.50 & -0.585 & -3.861 & $0.000^{*}$ \\
\hline \multicolumn{6}{|l|}{ Health motives } \\
\hline Health pressures & 3.53 & 3.15 & 0.381 & 2.211 & $0.028^{*}$ \\
\hline III-health avoidance & 5.10 & 4.65 & 0.414 & 3.133 & $0.002^{*}$ \\
\hline Positive health & 5.37 & 5.10 & 0.276 & 2.669 & $0.008^{*}$ \\
\hline \multicolumn{6}{|l|}{ Body-related motives } \\
\hline Weight management & 4.61 & 3.55 & 1.057 & 7.249 & $0.000^{*}$ \\
\hline Appearance & 4.61 & 4.22 & 0.397 & 3.027 & $0.003^{*}$ \\
\hline \multicolumn{6}{|l|}{ Fitness motives } \\
\hline Strength and endurance & 4.63 & 5.10 & -0.429 & -3.780 & $0.000^{*}$ \\
\hline Nimbleness & 4.60 & 4.80 & -0.199 & -1.756 & 0.080 \\
\hline
\end{tabular}

In terms of the mean differences, males scored higher than females on the interpersonal and fitness motives whilst females scored higher on the health and body-related motives. For the psychological motives males scored higher than females concerning the enjoyment and challenge of engaging in physical exercise, while their female counterparts were more motivated to engage in physical exercise as a stress reliever and to feel revitalised. Of the 14 motives for engaging in physical exercise, Generation $Y$ females scored statistically significantly higher than males on five motives, namely health pressure $(p=0.028<0.05)$, ill-health avoidance $(p=0.002<0.05)$, positive health $(p=0.008<0.05)$, weight management $(p=0.000<0.05)$ and appearance $(p=0.003<0.05)$. In contrast, Generation $Y$ males scored statistically significantly higher than females on the four motives of enjoyment $(p=0.026<0.05)$, challenge $(p=0.001<0.05)$, competition $(p=0.000<0.05)$, and strength and endurance $(p=0.000<0.05)$. This suggests that Generation $Y$ females are more motivated to engage in physical activity for extrinsic reasons, while Generation $Y$ males are more motivated by intrinsic motives.

\section{Discussion}

The aim of this study was to determine the difference between male and female Generation $Y$ students' motives for participating in physical activity. Of the 14 motives tested in the EMI-2, a significant difference between the genders was found on nine motives. This provides a clear indication of the value of targeting Generation $Y$ females and males separately with social marketing campaigns designed to promote a more active lifestyle.

Similar to previous studies, the findings of this study indicate that, with the exception of the intrinsically-oriented positive health motive, Generation $Y$ females tend to be mostly motivated to engage in physical activity for extrinsic reasons whilst, in contrast, their male counterparts are motivated by intrinsic goals. Physical activity and exercise promotion messages aimed at Generation $Y$ females should contain content to appeal to the body-related motives of weight management and appearance, and the health related motive of ill-health avoidance in order to stimulate their initial 
engagement in physical activity. Such messages should also attempt to appeal to the intrinsically-oriented positive health motives in order to encourage Generation $Y$ females' long-term physical activity participation.

Physical activity and exercise promotion messages targeting Generation $Y$ males should aim at appealing to their intrinsic motives. Promotion messages that stress the association between physical activity and strength and endurance and appeals that highlight the enjoyment, challenge and competitiveness involved in physical activity are likely to be successful in encouraging a more active lifestyle amongst Generation $Y$ males both in the short- and long-term.

In addition, physical education needs to be reintroduced into South Africa's school curricula and HEls need to provide their students with the time and facilities to participate in physical activity and exercise.

\section{Limitation and Implications for Further Research}

Limited studies were found that focussed specifically on the different motives why males and females participate in physical activity. The bulk of the literature reviewed only focussed on why females participate at a lower scale than males. Therefore, this study is important as it indicates specific motives for male and female participation in physical activity. When interpreting the results within this study it should be noted that there are some limitations. A non-probability convenience sample was used and this may be considered one of the most important limitations. Care should be taken in generalising the results as this type of sample does not necessarily allow for an objective assessment of the sample findings (Malhotra, 2010).

Although this study included respondents from eight of the nine provinces within South Africa, the study focussed exclusively on the HEl campuses in the Gauteng province. A cross-sectional method was used and it is only a snapshot in time and results within another area or time period could differ. This could also be considered another limitation. To overcome this limitation a longitudinal study would provide more in-depth information and results.

Furthermore, the study utilised a self-administered questionnaire which instead of actually observing their behaviour relied on the respondents to recall their abilities and actions.

This study has implications for further study. As a cross-sectional method was used it is recommended that a longitudinal study using probability sampling across all of South Africa's nine provinces that includes the observation data collections method could be completed in order to allow for more generalisability of the results.

\section{Conclusion}

Members of the youth; that is, the Generation $Y$ cohort, represent the future of South Africa, and their current and future health has important implications to that future. Given the known benefits of physical exercise to both physical and mental health, it is imperative that this cohort of the population be targeted with initiatives that will encourage them to engage in moderate to vigorous physical activities. The findings of this study suggest that Generation $Y$ males and females have different motives for engaging in physical activity and exercise, which suggests that they should be treated as different target markets for social marketing campaigns designed to foster a more active lifestyle amongst this cohort in South Africa.

\section{References}

Ahmed, D. (2012). Analysis of exercise motivation and locus of ausilty for exercise among interuniversity level team game players. International Journal of Behavioral Social and Movement Science, 1(2), 7-14.

Caspersen, C.J., Powell, K.E. \& Christenson, G.M. (1985). Physical Activity, Exercise, and Physical Fitness: Definitions and Distinctions for Health-Related Research. Public Health Reports. Mar-Apr; 100(2): 126-131.

Chalabaev, A., Sarrazin, P., Fontayne, P., Boiché, J. \& Clément-Guillotin, C. (2013). The influence of sex stereotypes and gender roles on participation and performance in sport and exercise: Review and future directions. Psychology of Sport and Exercise, 14, 136144.

Deci, E.L. \& Ryan, R.M. (1985). Intrincic Motivation and Self Determination in Human Behaviour. New York: Plenum.

Drake, K.M., Longacre, M.R., MacKenzie, T., Titus, L.J., Beach, M.L., Rundle, A.G. \& Dalton, M.A. (2014). High school sport programs differentially by sex. Journal of Sport and Health Science, 1, 1-7.

Ghooshchy, S.G., Kameli, S. \& Jahromi, M.K. (2011). The effect of sport activity and gender differences on self-perception in adolescents. Procedia Computer Science, 3, 1532-1534.

Ingledew, D.K. \& Markland, D. (2008), The role of motives in exercise participation. Psychology \& Health, 23(7), 807-828.

Ingledew, D.K., Markland, D. \& Medley, A.R. (1998). Exercise motives and stages of change. Journal of Health Psychology, 3, 477-489.

Kilpatrick, M., Herbert, E. \& Bartholomew, J. (2005). College students' motivation for physical activity: differentiating Men's and Women's 
motives for sport participation and exercise. Journal of American College Health. 54(2), 87-94.

Koivula, N. (1999). Sport participation: differences in motivation and actual participation due to gender typing. Journal of Sport Behaviour, 22(3), 360-380.

Malhotra, N.K. (2010). Marketing Research: An Applied Orientation (6th ed.). Upper Saddle River, NJ, USA: Pearson Prentice Hall.

Maltby, J. \& Day, L. (2001) The Relationship Between Exercise Motives and Psychological Well-Being, The Journal of Psychology, 135(6), 651-660.

Markert, J. (2004). Demographics of age: generational and cohort confusion. Journal of Current Issues and Research in Advertising, 26(2), 11-25.

Markland, D. \& Hardy, L. (1993). The exercise motivation inventory: Preliminary development and validity of a measure of individuals' reasons for participation in regular physical exercise. Personality and Individual Differences, 15(3), 289-296.

Markland, D. \& Ingledew, D.K. (1997). The measurement of exercise motives: Factorial validity and invariance across gender of a revised Exercise Motivations Inventory. British Journal of Health Psychology, 2(4), 361-376.

Mitchell, T.R. (1982). Motivation: New directions for theory, research and practice. The Academy of Management Review, 7(1): 80-88.

Nolan, V.T., Sandada, M. \& Surujlal, J. (2011). Percieved benefits and barriers to physical exercise participation of first year university students. African Journal of Physical, Health Education, Recreation and Dance, September (Supplement 1), 56-69.

Pallant, J. (2010). SPSS survival manual: a step by step guide to data analysis using SPSS for Windows (Version 10). Buckingham: Open University Press.

Rintaugu, E.G. \& Ngetich, E.D.K. (2012). Motivational gender differences in sport and exercise participation among university sport science students. Journal of Physical Education and Sport, 12(2), 180-187.

Rossouw, H.A., Grant, C.C. \& Viljoen, M. (2012). Overwight and obesity in children and adolescents: the South African problem. South African Journal of Science, 108 (5/6), 907-914.

Roxas, M.L. \& Stoneback, J.Y. (2004). The importance of gender across cultures in ethical decision-making. Journal of Business Ethics, 50, 149-165.

Ryan, R.M. \& Deci, E.L. (2000) Self-determination theory and the facilitation of intrinsic motivation, social development, and well-being. American Psychologist, 55(1), 68-78.

Ryan, R.M. \& Deci, E.L. (2008). Self-determination theory: A Macrotheory of human Motivation, development, and health. Canadian Psychology, 49(3), 182-185.

Sebire S.J., Standage, M. \& Vansteenkiste, M. (2009). Examining intrinsic versus extrinsic exercise goals: Cognitive, affective, and behavioral outcomes. Journal of Sport \& Exercise Psychology, 31, 189-210.

Shilubane, H.N., Ruiter, R.A.C., van den Borne, B., Sewpaul, R., James, S. \& Reddy, P.S. (2013). Suicide and related health risk behaviours among school learners in South Africa: results from the 20012 and 2008 national youth risk behaviour surveys. BioMed Central, 13(1), 926.

Spray, C.M., Wang, C.K.J., Biddle, S.J.H. \& Chatzisarantis, N.L.D. (2006). Understanding motivation in sport: An experimental test of achievement goal and self determination theories. European Journal of Sport Sciences, 6(1), 43-51.

Statistics South Africa. (2013). Mid-year population estimates: 2013 key indictors, statistical estimates: statistical release PO302. (online) at http://www.statssa.gov.za. 13 October 2013.

Vallerand, R.J. (2012). In Handbook of sport psychology (3rd ed) Tenenbaum, Gershon \& Eklund, Robert C. (eds.) Intrinsic and extrinsic motivation in sport and physical activity: A review and a look at the future (Chapter 3 pp 59-83). Hoboken, NJ: John Wiley and Sons

Vilhjalmsson, R. \& Kristjansdottir, G. (2003). Gender difference in physical activity in older children and adolescents: the central role of organized sport. Social Science and Medicine, 56, 363-374.

WHO (World Health Organization). 2011. Global recommendations on physical activity for health. (online) at http://www.who.int/leafletphysical-activity-recommendations-1.pdf. 10 August 2014.

WHO (World Health Organization). 2014a. Childhood overweight and obesity. (online) at http://www.who.int/dietphysicalactivity /childhood/en/en. 8 August 2014.

WHO (World Health Organization). 2014b. Physical activity and young people. (online) at http://www.who.int/dietphysicalactivity /factsheet young_people/en/. 7 August 2014 
